\title{
Empoderamento e participação da comunidade em políticas sociais
}

\section{Empowerment and Community participation in social policies}

Maria da Glória Gohn

Profa Dra UNINOVE, Profa Titular UNICAMP e Pesquisadora CNPq

E-mail: mgohnळuol.com.br

\section{Resumo}

A partir da apresentação de alguns conceitos que tem sido utilizados no debate contemporâneo sobre a participação da sociedade civil em esferas públicas, este texto objetiva analisar as formas organizacionais, as possibilidades e as tendências dessa participação, na relação sociedade/estado, destacando o espaço dos conselhos. Como não é possível entender o papel dos diferentes tipos de conselhos que existem no Brasil na atualidade, se não entendermos a reforma do Estado, o texto aborda também as Organizações Sociais (OSs) e as - Organizações da Sociedade Civil de Interesse Público (OSCIPs). Uma das principais conclusões apresentadas na análise do protagonismo civil nas políticas sociais é: a participação da sociedade civil na esfera pública - via conselhos e outras formas institucionalizadas - não é para substituir o Estado, mas para lutar para que este cumpra seu dever: propiciar educação, saúde e demais serviços sociais com qualidade, e para todos.

Palavras-chave: Protagonismo civil; Participação da sociedade civil; Políticas públicas sociais; Movimentos sociais; Conselhos de Gestão; Participação na esfera pública. 
Abstract

This article aims to analyze organizational forms, possibilities and tendencies of community participation, in the relation society/government, emphasizing the role of Councils. Since it is impossible to understand the different types of Councils that exist nowadays in Brazil, the text discusses the Social Organizations (OSs) and the Civil Society's Organizations of Public Interest (OSCIPs). One of the main conclusions presented is that the councils and other forms of community participations do not exist to substitute government, but to fight for community's rights: education, health and services of good quality. Key Words: Community participation; public social policies; social movements; councils.

\section{Localizando os Conceitos}

Objetivando fundamentar o universo referencial teórico da problemática em tela - a participação da sociedade civil em esferas públicas -, pontuaremos algumas considerações sobre alguns conceitos (ou categorias, já que alguns deles ainda não adquiriram o status teórico de um conceito). Eles são: sociedade civil e esfera pública, empoderamento, capital social e participação.

O conceito de sociedade civil já passou por várias concepções e significados, no Brasil e na América Latina. Ele vem sofrendo reformulações que seguem, em linhas gerais, momentos da conjuntura política nacional e a trajetória das lutas políticas e sociais do país. De uma forma geral, ele surge no período denominado trajetória das transições democráticas. 0 final dos anos 1970 destaca-se nesta trajetória porque foi quando o termo foi definitivamente introduzido no vocabulário político corrente e passou a ser objeto de elaboração teórica. Na linguagem política corrente, ele se tornou sinônimo de participação e organização da população civil do país na luta contra o regime militar. Este fato significou a construção de um outro referencial para o imaginário político nacional, fundado na crença de que a sociedade civil deveria se mobilizar e se organizar para alterar o status quo no plano estatal, dominado pelos militares e por um regime não democrático com políticas públicas que privilegiavam o grande capital, considerando apenas as demandas de parcelas das camadas médias e altas da população que alavancavam o processo de acumulação das emergentes indústrias filiais das empresas multinacionais. Este cenário estimulou o surgimento de inúmeras práticas coletivas no interior da sociedade civil, voltadas para a reivindicação de bens, serviços e direitos sociopolíticos, negados pelo regime político vigente.

Um dos principais eixos articuladores da sociedade civil, naquele período, foi dado pela noção de autonomia: tratava-se de organizar-se independentemente do estado (na maioria das vezes de costas para o mesmo). Na realidade, a autonomia também era um discurso estratégico para evitar alianças consideradas espúrias, para que o perfil de certos grupos da sociedade civil fosse configurado segundo alguns princípios, para que não houvesse reprodução de práticas autoritárias estatais e nem práticas consideradas co- 
mo superadas, como as baseadas no centralismo democrático das correntes de esquerda mais radicais ou mais tradicionais.O princípio da auto-determinação, componente fundamental num processo de autonomia, era exercitado de forma contraditória: frente à sociedade mais geral e ao estado, os movimentos, especialmente os populares, apresentavam-se como entes autônomos, com auto-determinação. Mas, internamente, havia diferenças entre as lideranças, suas bases e as assessorias externas que os apoiavam, de forma que a autonomia era relativa e dependente das assessorias (embora as assembléias fossem um elemento importante para construir ou referendar as agendas e pautas de luta).

A democracia direta e participativa, exercitada de forma autônoma, nos locais de moradia, trabalho, estudo etc. era tida como o modelo ideal para a construção de uma contra hegemonia ao poder dominante. Participar das práticas de organização da sociedade civil significava um ato de desobediência civil e de resistência ao regime político predominante.

Neste período, como bem analisou Sader (1988), novos atores entraram em cena, destacando-se os movimentos sociais populares urbanos reivindicatórios de bens e serviços públicos e por terra e moradia, assim como parcelas dos então chamados novos movimentos sociais, em luta pelo reconhecimento de direitos sociais e culturais modernos: raça, gênero, sexo, qualidade de vida, meio ambiente, segurança, direitos humanos etc. 0 pólo de identificação destes diferentes atores sociais era a reivindicação de mais liberdade e justiça social. O campo dos novos atores ampliou o leque dos sujeitos históricos em luta pois não se tratava mais de lutas concentradas nos sindicatos ou nos partidos políticos. Houve, portanto, uma ampliação e uma pluralização dos grupos organizados que redundaram na criação de movimentos, associações, instituições e Organizações não governamentais (ONGs).

Com a saída dos militares do poder, a partir de 1985, começa a se alterar o significado atribuído à sociedade civil. Com a progressiva abertura de canais de participação e de representação política, a partir das pressões populares, promovida pelos novos governantes, os movimentos sociais (especialmente os populares) perderam paulatinamente a centralidade que tinham nos discursos sobre a participação da sociedade civil. Passa a haver uma fragmentação do que denominou-se como "sujeito social histórico", centrado nos setores populares, fruto de uma aliança movimento sindical + movimento popular de bairro (trabalhadores e moradores), até então tidos como relevantes para o processo de mudança e transformação social. Surge uma pluralidade de novos atores, decorrentes de novas formas de associativismos que emergem na cena política. A autonomia dos membros da sociedade civil deixa de ser um eixo estruturante fundamental para a construção de uma sociedade democrática porque, com a saída dos militares e o retorno dos processos eleitorais democráticos, a sociedade política, traduzida por parcelas do poder institucionalizado no Estado e seus aparelhos, passa a ser objeto de desejo das forças políticas organizadas. Novos e antigos atores sociais fixarão suas metas de lutas e conquistas na sociedade política, especialmente nas políticas públicas.

Portanto, ao longo dos anos 1990 o campo da sociedade civil ampliou-se, na prática e nos discursos a seu respeito. O descentramento do sujeito e a emergência de uma pluralidade de atores conferiram a um outro conceito o de cidadania, a mesma relevância que tinha o conceito de autonomia nos anos 1980. A questão da cidadania - já estava posta nos anos 1980, tanto nas lutas pela redemocratização que levaram ao movimento Diretas Já, à Constituinte e à nova Carta Constitucional de 1988, destacando a questão dos direitos civis e políticos; como nas lutas populares por melhorias na qualidade de vida urbana.Nela a cidadania ganha novo contorno - como cidadania coletiva - e extrapola a demanda pelos direitos civis para incluir outros direitos, como os direitos sociais básicos, elementares, de primeira geração, já equacionados desde a Revolução Francesa, contidos nas demandas por casa, abrigo e comida; como direitos sociais modernos, relativos a condições de trabalho, educação, saúde etc. A cidadania nos anos 1990 foi incorporada nos discursos oficiais e ressignificada na direção próxima à idéia de participação civil, de exercício da civilidade, de responsabilidade social dos cidadãos como um todo, porque ela trata não apenas dos direitos, mas também de deveres, ela homogeneiza os atores. Estes deveres envolvem a tentativa de responsabilização dos cidadãos em arenas públicas, via parcerias nas políticas sociais governamentais. De um lado, isso é um 
ganho: significa o reconhecimento de novos atores em cena. De outro, é um risco, com o qual as lideranças progressistas da sociedade civil devem estar alerta: o de assumirem o papel que deve ser exercido pelo poder público estatal pois para tal ele é eleito, ou indicado, e os cidadãos pagam impostos.

No novo cenário, a sociedade civil se amplia para entrelaçar-se com a sociedade política, colaborando para o novo caráter contraditório e fragmentado que o Estado passa a ter nos anos 1990. Desenvolve-se o novo espaço público, denominado público não estatal, onde irão situar-se conselhos, fóruns, redes e articulações entre a sociedade civil e representantes do poder público para a gestão de parcelas da coisa pública que dizem respeito ao atendimento das demandas sociais. Essas demandas passam a ser tratadas como parte da "Questão Social" do país.

O "empoderamento" da comunidade, para que ela seja protagonista de sua própria história tem sido um termo que entrou para o jargão das políticas públicas e dos analistas, neste novo milênio. Trata-se de processos que tenham a capacidade de gerar processos de desenvolvimento auto-sustentável, com a mediação de agentes externos- os novos educadores sociais - atores fundamentais na organização e o desenvolvimento dos projetos. 0 novo processo tem ocorrido, predominantemente, sem articulações políticas mais amplas, principalmente com partidos políticos ou sindicatos.

Cumpre destacar que o significado da categoria "empowerment" ou empoderamento como tem sido traduzida no Brasil, não tem um caráter universal. Tanto poderá estar referindo-se ao processo de mobilizações e práticas destinadas a promover e impulsionar grupos e comunidades - no sentido de seu crescimento, autonomia, melhora gradual e progressiva de suas vidas (material e como seres humanos dotados de uma visão crítica da realidade social); como poderá referir-se a ações destinadas a promover simplesmente a pura integração dos excluídos, carentes e demandatários de bens elementares à sobrevivência, serviços públicos, atenção pessoal etc., em sistemas precários, que não contribuem para organizá-los - porque os atendem individualmente, numa ciranda interminável de projetos de ações sociais assistenciais. Vários fatores determinam a diferenciação dos dois tipos de processos e seus resultados, mas o principal deles é a natureza, o caráter e o sentido do proje- to social da (s) instituição (s) que promove (m) o processo de intervenção social. Estamos falando dos mediadores, das ONGse do terceiro setor de uma forma geral, das entidades que organizam os projetos, buscam os financiamentos, fazem as parcerias - com o governos, com outras entidades e organizações do terceiro setor da sociedade civil, com os organismos da cooperação internacional, e com os movimentos sociais. Esse último item é fundamental porque, dado os rumos que os movimentos tiveram nos anos 1980, principalmente os de caráter popular, e seus desdobramentos nos anos 1990 (alguns entrando em crise e desmobilizando-se, outros crescendo no rastro da crise por saber aproveitar as oportunidades políticas do momento), aliar-se ou fazer parceria com um movimento social, popular ou não, já é um indicador da natureza do projeto da entidade. Um outro indicador é o tipo de movimento (ou mais precisamente, qual movimento). Esse indicador pode ser captado segundo a trajetória histórica do movimento: origem, composição social, entidades articuladoras, redes sociais a que pertence, lutas que desenvolveu, projetos que elaborou, sucessos, perdas etc.

Robert Putnam tornou-se autor referencial nos estudos sobre a sociedade civil, ao final do século XX e início deste. Ele desenvolveu vários conceitos que são básicos para entender a questão do empoderamento, tais como comunidades cívicas e capital social. 0 conceito de comunidades cívicas foi caracterizado como "cidadãos atuantes e imbuídos de espírito público, por relações políticas igualitárias, por uma estrutura social firmada na confiança e na colaboração" (Putnam, 1993, p. 31). Putnam diz que os hábitos democráticos derivam de relações horizontais, espírito de reciprocidade e cooperação. Entretanto, a sua grande contribuição foi articular estas formulações com um outro conceito, que ganhou nova significação nos anos 1990: o de "capital social". Para ele, o conceito de comunidade é impregnado de individualismo e o de capital social firmou-se nos círculos intelectuais americanos para substituí-lo. Para Putman, capital social deve ser analisado por analogia com as noções de capital físico e capital humano, ferramentas e treinamento para intensificar a produtividade individual o cerne da idéia da teoria do capital social é que as redes têm valor...[..] Enquanto capital físico refere-se a objetos físicos e capital humano refere-se a propri- 
edades dos indivíduos, capital social refere-se à conexão entre indivíduos, redes sociais e às normas de reciprocidade e lealdade que nascem deles. Neste sentido, capital social é claramente relatado como algo chamado "virtude cívica". A diferença é que "capital social" chama atenção para o fato de que a virtude cívica é mais poderosa quando imersa numa densa rede de relações sociais recíprocas. Uma sociedade de muitos indivíduos virtuosos, mas isolados, não é necessariamente rica em capital social " (Putnam, 200o, p. 18-19).

Neste cenário, de novos temas, problemas e conceitos (ou de ressignificações disso tudo), resulta que, com as mudanças da conjuntura política na economia globalizada, o perfil e caráter da formação dos agentes mediadores ou educadores (as) sociais se alterou. Ser apenas "ativista", ter um largo currículo de militância ou de compromisso com certas lutas sociais, não é mais suficiente para qualificá-lo para o desempenho de suas tarefas. 0 novo educador deve ter outras qualificações além da militância. Para poder conhecer seus educandos, suas culturas, linguagens, valores e expectativas na vida, ele deve conhecer também a comunidade onde atua, ser sensível aos seus problemas. Para isso ele tem que dominar alguns conhecimentos. 0 educador tem que se formar e ser informado, não apenas na relação dialógica, mas em cursos de formação específica, combinados com cursos de formação geral (por isto os programas de pós-graduação estão repletos de educadores advindos das ONGs.

Para concluirmos nosso primeiro tópico, sobre os conceitos, seguem algumas considerações sobre a participação propriamente dita, a categoria mais abrangente. Os pressupostos gerais que sustentam nossas afirmações sobre a participação são:

a. Uma sociedade democrática só é possível via o caminho da participação dos indivíduos e grupos sociais organizados.

b. Não se muda a sociedade apenas com a participação no plano local, micro, mas é a partir do plano micro que se dá o processo de mudança e transformação na sociedade.

c. É no plano local, especialmente num dado território, que se concentram as energias e forças sociais da comunidade, constituindo o poder local daquela região; no local onde ocorrem as experiências, ele é a fonte do verdadeiro capital social, aquele que nasce e se alimenta da solidariedade como valor humano. 0 local gera capital social quando gera autoconfiança nos indivíduos de uma localidade, para que superem suas dificuldades. Gera, junto com a solidariedade, coesão social, forças emancipatórias, fontes para mudanças e transformação social.

d. É no território local que se localizam instituições importantes no cotidiano de vida da população, como as escolas, os postos de saúde etc. Mas o poder local de uma comunidade não existe a priori, tem que ser organizado, adensado em função de objetivos que respeitem as culturas e diversidades locais, que criem laços de pertencimento e identidade socio-cultural e política.

Existem, também algumas premissas básicas relativas à participação da sociedade civil das quais se destaca a participação da sociedade civil na esfera pública - via conselhos e outras formas institucionalizadas - não é para substituir o Estado, mas para lutar para que este cumpra seu dever: propiciar educação, saúde e demais serviços sociais com QUALIDA$\mathrm{DE}$, e para todos. Essa participação deve ser ativa e considerar a experiência de cada cidadão que nela se insere e não tratá-los como corpos amorfos a serem enquadrados em estruturas prévias, num modelo pragmatista.

Dewey já dizia: Só é experiência o que refletimos, o que aprendemos. O que se sedimenta na memória. É aquilo que vem alimentar o sonho, a utopia, a esperança, a ilusão. Rudá Ricci, em exposição em Belo Horizonte (2003) afirmou: “ o mundo da experiência é o da memória coletiva, da solidariedade, aquela solidariedade que gera identidade". Neste mundo há ética, moral, valores. 0 pragmatismo não gera experiência porque refere-se a ações tópicas, imediatistas, sem profundidade, sem reflexão. 0 pragmatismo se alimenta de índices estatísticos e não da experiência, alimenta-se de táticas imediatistas e busca do lucro e não da experiência acumulada via processos participativos. 0 pragmatismo não leva à construção de alternativas porque ele é imobilizador, não apresenta saídas. A única saída é a espera: que façam por nós. Ele não preconiza a participação, congela- a.

Em síntese, estamos vivendo um novo momento na trajetória do associativismo brasileiro. Não podemos perder de vista que essas novas redes associativistas também estão contribuindo para o empower- 
ment (empoderamento) dos setores populares em nossa sociedade, ainda que de forma muito pontual por trabalharem com projetos focalizados e tratarem os demandatários excluídos como clientes de serviços sociais. Mas os problemas sociais são graves e necessitam respostas urgentes. Por isso o terceiro setor de perfil mais corporativo, estruturado com o apoio de grandes grupos ou companhias empresariais, atuando nas franjas da nova economia social, segundo as regras da economia de mercado, tende a predominar sobre os movimentos e as ONGsque trabalham de forma processual, com ênfase na capacidade da sociedade se organizar e defender seus interesses, na construção de novos atores sociais que representam distintos interesses e que atuam em defesa da cidadania. Um dos problemas dessas instituições com perfil democrático e participativo é que seu impacto na realidade é lento. É preciso dinamizá-las.

Disso tudo resulta um cenário contraditório, no qual convivem entidades que buscam a mera integração dos excluídos por meio da participação comunitária em políticas sociais exclusivamente compensatórias; com entidades, redes e fóruns sociais que buscam a transformação social por meio da mudança do modelo de desenvolvimento que impera no País, inspirados num novo modelo civilizatório no qual a cidadania, a ética, a justiça e a igualdade social sejam imperativos, prioritários e inegociáveis.

A importância da participação da sociedade civil se faz neste contexto não apenas para ocupar espaços antes dominados por representantes de interesses econômicos, encravados no Estado e seus aparelhos. A importância se faz para democratizar a gestão da coisa pública, para inverter as prioridades das administrações no sentido de políticas que atendam não apenas as questões emergências, a partir do espólio de recursos miseráveis destinados às áreas sociais.

O protagonismo de alguns atores da sociedade civil no que se refere às políticas públicas: Os Movimentos Sociais e as Organizações não governamentais a partir dos anos 1990

Creio que é interessante voltarmos um pouco na História e dividirmos a questão do protagonismo dos movimentos sociais no Brasil, a partir dos anos 1990, quando houve uma perda de sua visibilidade política no urbano, em três momentos: de 1990 a 1995; de 1995 a $2000 ;$ e do início deste novo século até os dias atuais.
Vários analistas diagnosticaram que houve crise nos movimentos sociais populares urbanos, nos primeiros cinco anos dos anos 1990, no sentido que eles tiveram reduzida, naqueles anos, parte do poder de pressão direta que haviam conquistado nos anos 1980. Isso se deu em função de vários fatos novos, que explicam as alterações que ocorreram em suas dinâmicas cotidianas. É bom lembrar que o país saía de uma etapa de conquista de novos direitos constitucionais, a maioria dos quais precisava ser regulamentada. A volta das eleições diretas em todos os níveis governamentais também alterou a dinâmica das lutas sociais porque tratava-se agora de democratizar os espaços públicos estatais. A necessidade de atuação no plano institucional e governamental, aumentou, não apenas nos locais que passaram a ser administrados por governos populares, fundamentalmente, no plano federal, locus de debate e encaminhamento das conquistas obtidas na Carta de 88, para que viessem a ser implantadas. E todos nós sabemos que o governo federal, naquele mesmo período, passou a implementar ou a aprofundar, em todos os níveis, as políticas neoliberais. Para complicar mais ainda o cenário, essas políticas geraram desemprego, aumento da pobreza e da violência, urbana e rural.

Houve até quem preconizasse, naqueles anos, que a fase das mobilizações nas ruas estava ultrapassada. Correspondia a uma etapa já superada, pois o regime militar havia caído e se tratava agora de atuar apenas no plano institucional. A educação popular e o trabalho de base junto a grupos populares também passou a receber críticas, seria algo também já superado, justificável apenas na década anterior, naquele momento a página teria que ser virada. Conseqüentemente, a visibilidade externa dos movimentos populares urbanos, na mídia e na sociedade como um todo, refluiu naquele período. Ao mesmo tempo, um outro sujeito sociopolítico, advindo dos movimentos sociais populares do campo, ganhava força: os sem-terra, especialmente o MST. Portanto, quando se falava de "crise dos movimentos sociais urbanos", nos primeiros anos da década de 1990, não significava o desaparecimento deles, e nem o seu enfraquecimento enquanto atores sociopolíticos relevantes, mas sim uma rearticulação, interna e externa, de seu papel na sociedade. As mudanças na conjuntura política levaram também à emergência, ou ao fortalecimento, de outros atores 
sociais relevantes na sociedade civil, tais como as ONGs e outras entidades do Terceiro Setor. Os movimentos populares passaram a ter outros aliados, e/ ou competidores, na disputa entre os grupos organizados para demandar as necessidades sociais ao poder público, ou organizar trabalhos coletivos para resolver estas demandas entre os próprios necessitados. Para finalizar as observações sobre o cenário dos movimentos populares, nos primeiros anos da década de 1990, não podemos deixar de registrar que houve tensões entre as lideranças na condução dos movimentos urbanos, principalmente em relação a questões como: institucionalização, participação ou não em conselhos propostos ou criados pelo poder público, participação em programas governamentais, etc. 0 fato de várias lideranças ascenderem a cargos no poder público, ou ao parlamento, também teve alguma influência na nova dinâmica dos movimentos. Este novo cenário gerou a necessidade de articulações e a maioria dos movimentos, rurais ou urbanos, passaram a atuar em redes e a construir agendas anuais de congressos e manifestações públicas, como o Grito dos Excluídos, por exemplo.

Em suma, no interior dos movimentos expressava-se uma crise maior, que não era deles mas refletiase no seu cotidiano, que o país atravessava: o desmonte de políticas sociais pelas políticas neoliberais e sua substituição por outras políticas, em parceria com ONGse outras entidades do Terceiro Setor; a fragmentação da sociedade pela desorganização ou flexibilização do mercado de trabalho levando ao crescimento do setor informal; a defasagem na qualificação do mercado de trabalho face a era da tecnologia, comunicações e informação, levando a novas exigências no campo da educação, formal e não formal, face ao mundo globalizado etc. Portanto, a crise expressava os novos arranjos na busca de renovação, de adaptação à nova conjuntura e às mudanças no mundo do trabalho, de reposicionamento frente às novas políticas públicas.

Na segunda metade dos anos 1990, novos ingredientes foram acrescentados, alterando ainda mais a dinâmica dos movimentos sociais em geral, e dos populares em particular. Começo citando as crises econômicas internas, em movimentos populares e ONGscidadãs, que os levaram a repensar seu planos, planejamentos de ação, estratégias e forma de atuar, elabo- ração de planejamentos estratégicos etc. Algumas entidades de apoio aos movimentos até fecharam suas portas, outras fizeram enxugamentos em termos de regiões de atuação, se fundiram com outras, ou ainda deslocaram suas áreas de atuação para setores específicos, dentro do leque dos programas sociais institucionalizados, governamentais ou de apoio advindo da cooperação internacional. Novas pautas foram introduzidas, tais como a de se trabalhar com os excluídos sobre questões de gênero, etnia, idades etc. As dificuldades de apoios para manter estruturas mínimas, ou a necessidade de re-orientar suas ações, em função de novas diretrizes e regras da cooperação internacional, não deixavam sobra de tempo para as lideranças se articularem com a população. Os novos tempos, de desemprego e aumento da violência urbana, assim como o crescimento de redes de poder paralelo nas regiões pobres, ligados ao narcotráfico de drogas e outros, também colaboraram, e muito, para desmotivar a população necessitada para participar de reuniões ou outras atividades dos movimentos.

Registre-se ainda que a nova política de distribuição e gestão dos fundos públicos, em parceria com a sociedade organizada, focalizados não em áreas sociais (como moradia, saúde, educação etc.), mas em projetos pontualizados, como crianças, jovens, mulheres etc., contribuiu para desorganizar as antigas formas dos movimentos fazerem suas demandas e reivindicações. A palavra de ordem destes projetos e programas passaram a ser: ser propositivo e não apenas reivindicativo, ser ativo e não apenas um passivo reivindicante. Muitos movimentos se transformaram em ONGsou se incorporaram às ONGsque já os apoiavam. A atuação por projetos exige resultados e tem prazos. Criou-se uma nova gramática na qual mobilizar deixou de ser para o desenvolvimento de uma consciência crítica ou para protestar nas ruas. Mobilizar passou a ser sinônimo de arregimentar e organizar a população para participar de programas e projetos sociais, a maioria dos quais já vinha totalmente pronta e atendia a pequenas parcelas da população. 0 militante foi se transformando no ativista organizador das clientelas usuárias dos serviços sociais.

De uma certa forma, programas como o Saúde da Família (PSF) podem ser utilizados como exemplos deste novo perfil de atuação da sociedade civil organizada via a mediação das ONGse outras instituições. 
Em 2003, o PSF mantinha 15 mil equipes em todo o Brasil sendo 690 só na cidade de São Paulo, onde havia 3544 agentes comunitários. Exige-se deste novo ativista uma atuação integrada a uma equipe médica e, ao mesmo tempo, um trabalho prévio de cadastramento da população e suas necessidades locais. Para o agente, trata-se de um espaço de trabalho e renda, ainda que por certo período, dependendo de seu contrato com uma ONGsque o selecionou. A maioria destes agentes não tem experiência associativa anterior e nem cursos de formação ou de capacitação sobre como poderá ser uma participação cidadã. Quanto ao serviço público prestado à população, via essa nova modalidade de prestação de serviços a população, observa-se um movimento contraditório: de um lado, um avanço pelo fato de se ter contatos diretos com agentes comunitários que conhecem a realidade dos problemas locais, de se ter a possibilidade de um "atendimento personalizado" De outro lado, esse atendimento se inscreve num cenário de escassez de recursos humanos e material, e o que deveria ser um acréscimo, de fato, é uma subtração porque estes agentes têm que realizar outras tarefas nos postos de atendimento para suprir pessoal que deveria estar trabalhando como funcionários regulares. Faltam aos agentes comunitários formação e informação e a socialização das informações,em geral, é muito difícil. Na formação não bastam aspectos biológicos, relativos às doenças, deve-se ter uma prática que os capacite a fazer uma leitura mínima do mundo, da vida e seus problemas, do entendimento de seu papel no processo. Para agir segundo um pretenso modelo que criou os agentes comunitários, eles deveriam entender certos códigos de conduta e de linguagem, estar articulados em redes de formação. Eles não podem ser um agente comunitário "institucionalizado", que perdeu a identidade com seu território de origem, que não tem laços de pertencimento locais, que só se preocupa com a rotina do trabalho segundo seu vínculo empregatício. Crevelim (2004) faz um trabalho minucioso a este respeito; ela concluiu que há limites no processo de participação dado não apenas pela falta de infra-estrutura, mas falta também uma cultura de participação, assim como falta vontade política para que a cidadania de fato seja exercida. A questão dos Conselhos

Não é possível entender o papel dos diferentes tipos de conselhos que existem no Brasil, na atualida- de, se não entendermos a reforma do Estado e, para isso, é preciso entender o que são as Organizações Sociais (OSs) e as Organizações da Sociedade Civil de Interesse Público (OSCIPs). As Organizações Sociais foram criadas por lei em maio de 1998 para reestruturarem o aparelho do Estado em todos os níveis. No nível Federal, parcelas do próprio Estado poderão deixar de fazer parte do aparelho estatal e se tornar prestadoras de serviços públicos, ou parte das atividades do Estado passarão a fazer parcerias com entidades do chamado Terceiro Setor (leia-se: ONGs organizações e associações comunitárias ou filantrópicas, e outras entidades sem fins lucrativos). Não é toda e qualquer ONGs que pode ser considerada como parte do Terceiro Setor, mas sim aquelas com o perfil do novo associativismo civil dos anos 1990. Um perfil diferente das antigas ONGs dos anos 1980, que tinham fortes características reivindicativas, participativas e militantes. 0 novo perfil desenha um tipo de entidade mais voltada para a prestação de serviços, atuando segundo projetos, dentro de planejamentos estratégicos, buscando parcerias com o Estado e empresas da sociedade civil.

A forma de realização das parcerias são via as OSs - Organizações Sociais e as OSCIPs- Organizações da Sociedade Civil de Interesse Público. A Reforma do Estado elaborada pelo ex-Ministro Bresser Pereira, no MARE, durante a gestão do Presidente Fernando Henrique Cardoso, previa que as políticas públicas para as áreas de Cultura, Educação, Lazer, Esporte, Ciência e Tecnologia viessem a ser apenas gerenciadas e não mais executadas pelo Estado. As OSs e as OSCIPs são parte de um modelo político e de uma orientação filosófica nos quais o Estado é responsável apenas pelo gerenciamento e controle das políticas públicas e não pela execução das mesmas. 0 Estado deixa de lado o papel de executor, ou prestador direto de serviços, e passa a ter função de promotor e regulador. Quem vai executar estas políticas serão justamente as OSs e as OSCIPs, que se constituem e se qualificam como tal - através de um contrato de gestão, no caso das OSs, firmado entre o Terceiro Setor e o poder público; ou através de um desmembramento de parte do próprio poder público, via parcerias com as OSCIPs .

As OSs e as OSCIPs fazem parte de um novo modelo de gestão pública e, a longo prazo, a reforma do 
estado prevê que toda a área social deve adotar essas nova lógica e forma de operar na administração pública propriamente dita. As OSs, por exemplo, se inserem no marco legal das associações sem fins lucrativos, cuja lei foi regulamentada e promulgada em 1999. Elas são pessoas jurídicas de direito privado, estando portanto fora do âmbito dos órgãos públicos. Seus funcionários poderão vir de estatais, mas na OS eles não estarão mais sob o Regime Jurídico Único dos Servidores Públicos, não serão mais, portanto, funcionários públicos no sentido lato do termo. Mas as OSs recebem recursos públicos consignados no Orçamento da União ou do respectivo estado, constituindo receita própria. A alocação destes recursos e a execução orçamentária das OSs não estão submetidas aos ditames da execução orçamentária, financeira e contábil, como os demais órgãos públicos, que têm de submeter-se a um controle processualístico. Seu controle se dá pelos seus resultados, por meio da avaliação das metas que elas estabeleceram. Além disso, as OSs recebem toda a infra-estrutura montada, que antes servia de base a um órgão estatal na prestação do serviço. Registre-se ainda que as OSs ou OSCIPs têm que se qualificar para se constituírem como operantes das novas orientações políticas. Na prática, são ONGs e organizações do Terceiro Setor que estão se qualificando. Segundo Traldi (2003), até Julho de 2002, 1068 entidades não-governamentais entraram com o processo de qualificação como OSCIP; destas, apenas 563 foram deferidas, e 505 (quase a metade), foram indeferidas. Se analisarmos a área de atuação das 563 entidades deferidas observa-se que o maior número atua na área assistencial (187), seguida pela ambiental (107). Em terceiro lugar tem-se as creditícias (82) e em quarto as educacionais (66, correspondendo a $13 \%$ do universo total). As outras áreas são: cultura (43), pesquisa (36),saúde (32) e jurídica (10).

Um dado que causa espanto é o fato das OSs se qualificarem a partir de um simples pedido ao Ministério do Planejamento que, uma vez aprovado, remete ao Ministério da Justiça. O contrato de gestão não passa pelo Legislativo, fica no âmbito do Executivo.

Houve um grande debate que identificou este processo como uma privatização, ou terceirização do Estado, e parte fundamental das reformas neoliberais, com seus defensores e críticos. Dentro dos objetivos deste artigo, não entraremos neste debate, mas resta assinalar que, a Reforma do Estado, ao final dos anos 1990, não incluiu os Conselhos Gestores no processo de contratação das OSs constituídas para gerirem os serviços públicos e as atividades publicizadas; ou da qualificação de uma OS. Os Conselhos gestores, mesmo os que têm poder deliberativo, irão analisar o resultado de um processo - quando forem avaliar uma OS, por exemplo, do qual eles não participaram no início, na própria constituição da OS.

Mas, por que isto é importante? Por que deixamos a discussão dos conselhos de lado e enveredamos pelo tema das Organizações Sociais? Porque, a médio prazo, os serviços na área social que saírem da órbita de execução direta pelo Estado deverão ser de responsabilidade das OSs e dos Conselhos de Gestão que estas precisam instalar. Os contratos de gestão firmados por um determinado período também teriam um Conselho relacionado com o Conselho do Município, na área social correspondente. Uma nova modalidade de gestão do que é público surge desta articulação e desta rede de formas de representação e participação, que são muito mais complexas do que outras formas implantadas no passado, na relação povo-governo, na administração pública. Conceitos novos estão sendo criados para expressarem as novas formas, tais como o de governança (local, regional, nacional, global).

Apesar de todos os obstáculos, acreditamos firmemente que a interlocução e o exercício da vida política/cultural, na esfera pública, contribui para o desenvolvimento de uma nova CULTURA POLÍTICA PÚBLICA no país, construída a partir de critérios do campo dos direitos (sociais, econômicos, políticos e culturais), uma nova cultura ética com civilidade e respeito ao outro. Essa nova cultura política se contrapõe à tradição autoritária que desconhece a existência de esferas públicas, assim como se contrapõe, também, às práticas clientelistas ou corporativas de grupos patrimonialistas, oligárquicos, ou modernos/privatistas. Trata-se de uma cultura política gerada por processos nos quais os diferentes interesses são reconhecidos, representados e negociados, via mediações sociopolíticas e culturais.

Os conselheiros devem ter formação e consciência crítica, para terem como meta o entendimento do processo onde se inserem; entenderem, por exemplo, a questão dos fundos financeiros públicos e os critérios que deveriam pautar seu uso para a eliminação 
da pobreza e das desigualdades sociais, para o atendimento das necessidades da população, segundo escalas de urgências e emergências. Os mecanismos de competição do mercado não irão resolver as desigualdades sociais, serão políticas públicas democráticas, não excludentes, formuladas a partir de modelos que não se alicercem no lucro, que poderão minorar os problemas sociais.

A esfera pública deve ser, também, um espaço para os cidadãos organizados exercerem fiscalização e vigilância sobre os poderes públicos constituídos via eleições, concursos ou critérios consuetudinários. Por isso, as Promotorias Públicas e o Ministério Público ganharam força para se expressarem, nos últimos anos. Eles são a instância para que se recorra no caso de não observância das ações públicas. A ampliação da esfera pública contribui para a formação de consensos alcançados argumentativamente, numa gestão social compartilhada, gestada a partir de exercícios públicos deliberativos.

A temática da esfera pública auxilia-nos a entender a importância da sociedade civil organizada, pois ela é um dos atores fundamentais do Poder Local. A esfera pública adentra nos espaços públicos, dialogando com os seus grupos organizados e realizando parcerias em ações conjuntas com os mesmos. Certamente que, se os atores participantes dos pactos e parcerias na esfera pública advirem de sujeitos políticos organizados nos espaços públicos da sociedade civil, com pouca representatividade, fracos laços de pertencimento social, projetos, valores e visões de mundo não cidadãos, voltados para coletivos organizados apenas como grupos de interesses, grupos de pressão, ou grupos focais que atuam segundo regras exclusivas do mercado, seus resultados e impactos, não podese esperar avanços na democratização das relações povo-governo e nem mudanças sociais significativas em direção a projetos emancipatórios, que contemplem a justiça, a igualdade etc. Esta forma de atuação tem como objetivo alterar, progressivamente, a subordinação (ou apatia) da sociedade civil frente ao Estado. Altera, também, a cultura de participação da sociedade civil, no sentido dos grupos progressistas priorizarem pautas coletivas, deixando de lado "picuinhas" e divergências em torno de interesses particulares e corporativistas. Ser representante das demandas e interesses da sociedade implica em realizar mediações e intermediações. Decisões políticas democráticas envolvem mudanças no campo estatal como da própria sociedade civil, desde que certos princípios democráticos não sejam abandonados, mas sejam marcos referenciais, quais sejam: justiça, liberdade, solidariedade e igualdade com respeito às diferenças.

Tudo isso pode ser resumido na expressão: PARTICIPAÇÃO CIDADÃ, aquela que redefine laços entre o espaço institucional e as práticas da sociedade civil organizada, de forma que não haja nem a recusa à participação da sociedade civil organizada, nem a participação movida pela polaridade do antagonismo a priori, e nem sua absorção pela máquina estatal, porque o Estado reconhece a existência dos conflitos na sociedade e as divergências nas formas de equacionamento e resolução das questões sociais, entre os diferentes grupos, e participa da arena de negociação entre eles. Os Conselhos são uma das modalidades para o exercício da cidadania.

Cumpre destacar, entretanto, que a participação da sociedade civil não pode, nunca, se resumir à participação nos espaços dos conselhos ou outros criados na esfera pública. Até para que essa participação seja qualificada - no sentido exposto acima - ela deverá advir de estruturas participativas organizadas autonomamente na sociedade civil. $\mathrm{O}$ chamado trabalho de base é fundamental para alimentar e fortalecer a representação coletiva nos colegiados da esfera pública. Essa esfera pública não pode ser vista como um degrau superior, que surgiu para eliminar ou superar formas e níveis de mobilização e organização que existiram na sociedade brasileira nos anos 1970/80, pois esta é uma visão etapista, linear e evolutiva.

\section{Referências}

ARAÚJO, H. C. S. Contribuição à epidemiologia e prophylaxia da lepra no Norte do Brasil. Memórias do Instituto Oswaldo Cruz, Rio de Janeiro, v. 27, n. 3, p.165, 1933.

AVELLEIRA, J. C. R.; NERY, J. A. O tratamento da hanseníase. Rio Dermatológico, Rio de Janeiro, v. 2, n. 3, p. 2-3, 1998.

BASSEWITZ, E. V. A questão da lepra no Rio Grande do Sul. Arquivos Riograndenses de Medicina, Porto Alegre, v. 6, n.1, p.10-12, 1927. 
BÍBLIA Sagrada. 82. ed. São Paulo: Editora Ave Maria, 1992.

BRASIL. Ministério da Saúde. Controle da Hanseníase: uma proposta de integração ensino-serviço. Rio de Janeiro: DNDS/NUTES, 1989.

BRASIL. Ministério da Saúde. Manual de Prevenção de Incapacidades. Brasília: Área técnica de Dermatologia Sanitária, 2001.

BRASIL. Ministério da Saúde. Saúde Brasil, Edição n.95, abr. 2004.

CALMON, P. História da civilização brasileira. Rio de Janeiro, 1940. p.119.

CAMELLO, R. S. Levantamento de causas do abandono de tratamento de hanseníase no município de Porto Alegre. Porto Alegre, 2002. Monografia. Curso de especialização em Epidemiologia com ênfase em vigilância em Saúde, ESP/UFPEL.

CARNEIRO, G. História da dermatologia no Brasil: dados sobre a especialidade e a sociedade científica; edição comemorativa dos 90 anos da fundação da Sociedade Brasileira de Dermatologia. Rio de Janeiro: Sociedade Brasileira de Dermatologia, 2002.

CARVALHO, A. S. História da lepra em Portugal. Porto, 1932.

CUNHA, A. Z. S. Hanseníase: a história de um problema de saúde pública. Santa Cruz do Sul, 1997. Dissertação (Mestrado em Desenvolvimento Regional) - Universidade Santa Cruz do Sul.

DANIELSEN, D. C.; BOECK, W. Traité de la Spédalskdhed. Paris: Chez. J.B. Bailliére, 1848.

EIDT, L. M. O mundo da vida do ser hanseniano: sentimentos e vivências. Porto Alegre, 20oo. Dissertação (Mestrado em Educação) - Faculdade de Educação, PUCRS.

FAILLACE, M. Do conceito da profilaxia da lepra. Monografia. Porto Alegre, 1933. [Mimeo]

FERREIRA, J. et al. Controle da hanseníase num sistema integrado de saúde. Boletin de la Oficina Sanitária Panamericana, Washington, v.95, n.6, p.507$515,1983$.
FOSS, N. T. Hanseníase: aspectos clínicos, imunológicos e terapêuticos. Anais brasileiros de Dermatologia, Rio de Janeiro, v.74, n.2, p.113-19, 1999.

GOMES, A. C. B. O processo de Armauer Hansen. Jornal do Conselho Regional de Medicina do Rio Grande do Sul, Porto Alegre, p.13, fev. 2000.

GOMES, A. C. B. et al. Hanseníase no Rio Grande do Sul: situação atual. Boletim Trimestral de Dermatologia da Sociedade Brasileira de Dermatologia Secção RS, v.8, n.3o, p.5, 1998.

GUEDES, T. C. Considerações sobre a lepra e sua prophylaxia. Tese. Bahia, 1930.

JOHNSTON, P. BC's "Island of death" marked a sad chapter in Canada's medical history. Canadian Medical Association Journal, Montreal, v.152, n.6, p.951-952, 1995.

JOPLING, W. H.; McDOUGALL, A. C. Manual de hanseníase. 4. ed. Rio de Janeiro: Livraria Atheneu, 1991.

JORNAL DO MORHAN. Órgão oficial de divulgação do movimento de reintegração das pessoas atingidas pela Hanseníase. n. 35, jul/ago. 2000.

MAGALHÃES, J. L. A morphéa no Brasil. Rio de Janeiro, 1882.

MATTA, A. Escorço histórico da lepra no Estado do Amazonas. Ciência Médica, Rio de Janeiro, v. 7, n.4, p.181, 1924 .

MAURANO, F. História da lepra em São Paulo. São Paulo, 1939.

MAURANO, F. Tratado de Leprologia - Volume 1 - História da Lepra No Brasil e sua Distribuição Geográfica. Rio de Janeiro: Serviço Nacional de Lepra, 1944.

MONTEIRO, Y. N. Hanseníase: história e poder no Estado de São Paulo. Hansenologia Intenationalis, São Paulo, v.12, n.1, p.1-7, 1987.

NOGUEIRA, W. et al. Perspectivas da eliminação da hanseníase. Hansenologia Intenationalis, São Paulo, v.20, n.1, p.19-28, 1995.

OPROMOLLA, D. V. A. Noções de hansenologia. Bauru: Centro de Estudos Dr. Reynaldo Quagliato, 1981. 
OPROMOLLA, D.V. A. Noções de Hansenologia. Bauru: Centro de Estudos Dr. Reynaldo Quagliato, 2000.

ORGANIZACIÓN PANAMERICANA DE LA SALUD/ ORGANIZACION MUNDIAL DE LA SALUD (OPS/ OMS). Lepra al dia: situacion de la eliminación de la lepra en algunos paises de la America Latina. Boletin Eliminación de la Lepra de las Ameritas, n. 9, nov.2001.

PERES, M. P. Experiência com poliquimioterapia em hanseníase no Estado do Rio Grande do Sul. Boletim Trimestral de Dermatologia da Sociedade Brasileira de Dermatologia - Secção RS, v. 7, n.2, p.6-7, 1997.

PINHEIRO, M. F. B. Irmandade do S.S. da Freguezia da N.S. da Candelária e suas repartições, coro, caridade e Hospital dos Lázaros. Rio de Janeiro, 1894.

PINTO, P. G. H. R. O estigma do pecado: a lepra durante a Idade Média. PHYSIS - Revista de Saúde Coletiva, Rio de Janeiro, v. 5, n.1, p.131-144, 1995.

RODRIGUES, A. L. et al. Guia para a utilização de medicamentos e imunobiológicos na área de Hanseníase. Brasília: Ministério da Saúde, 2000.

ROTBERG, A. A antiga, permanente e poderosa antieducação com a palavra "lepra" e sua frustração através de nova terminologia. Doença Hanseniase, São Paulo, v.1, n.1, p.26-33, 1977.
SANTIAGO, P.E. A lepra em Santa Catarina. Revista Combate à Lepra, Rio de Janeiro, v. 6, n.4, 1941.

SERVIÇO NACIONAL DE LEPRA. Manual de Leprologia. Rio de Janeiro: Departamento Nacional de Saúde, 1960.

SKINSNES, O. Imunopathology os leprosy - The century in rewiew. International Journal of Leprosy, Bloomfield, v. 42, p. 329-36o, 1973.

SOUZA ARAÚJO, H. C. Memórias do Instituto Oswaldo Cruz. Rio de Janeiro: Departamento de Imprensa Nacional, 1918.

SOUZA ARAÚJO, H. C. História da lepra no Brasil. Rio de Janeiro: Imprensa Nacional, 1946.

TALHARI, S.; NEVES, R.G. Hanseníase. 3. ed. Manaus: Gráfica Tropical, 1997.

TERRA, F. Esboço histórico da lepra no Brasil. Anais Brasileiros de Dermatologia, Rio de Janeiro, v. 2, n.1, p.III-IV, 1926.

VEIGA, P. J. X. Ephemérides mineiras (1664-1897). Ouro Preto, 1897.

VELLOSO, A. P.; ANDRADE, V. Hanseníase: curar para eliminar. Porto Alegre: Edição das autoras, 2002.

VIRMOND, M. A hanseníase como doença de baixa prevalência. Hanseologia Internationalis, Lima, v. 20, n.2, p.27-35, 1995.

Recebido em: 03/05/2004

Aprovado em: 08/06/2004 